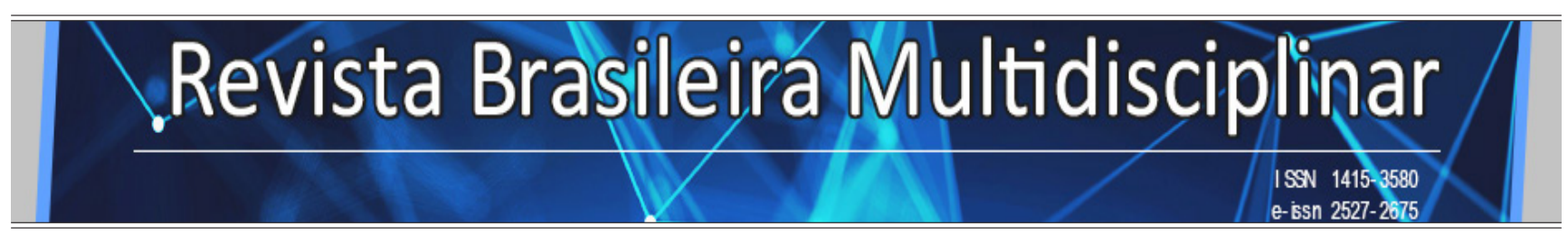

http://revistarebram.com/index.php/revistauniara

\title{
INTERVENÇ̃̃o EDUCATIVA NA ATENÇão PRÉ-NATAL E O CUIDADO AO RECÉM-NASCIDO
}

Amanda de Assunção Lino*; Carla Regina de Almeida Corrêa**; Jamile Claro de Castro Bussadori ${ }^{* *}$; Maria Cândida de Carvalho Furtado ${ }^{* *}$; Luciana Mara Monti Fonseca ${ }^{* * *}$; Monika Wernet ${ }^{* * * *}$.

* Doutoranda em Enfermagem em Saúde Pública pela escola de Enfermagem de Ribeirão Preto.

** Mestrado em Programa de Pós-Graduação em Enfermagem pela Universidade Federal de São Carlos, Brasil.

*** Doutorado em Enfermagem em Saúde Pública pela Universidade de São Paulo, Brasil.

**** Doutorado em Doutorado pela Escola de Enfermagem da Universidade de São Paulo, Brasil.

*Autor para correspondência e-mail: amanda.assuncaolino@gmail.com

\section{Palavras-chave}

Educação em saúde Saúde materno-infantil

Cuidado pré-natal

Cuidado da criança

Enfermagem Neonatal

\section{KEYWORDS}

Health education

Maternal and child health

Prenatal care

Child care

Neonatal Nursing

\section{RESUMO}

Objetivou-se descrever a influência de ação educativa desenvolvida no pré-natal no manejo de intercorrências no cuidado do filho. Trata-se de um estudo de abordagem qualitativo apoiado nos referenciais do Interacionismo Simbólico e Análise de Conteúdo Temática de Bardin. Sete puérperas que integraram a intervenção educativa no pré-natal foram entrevistadas sobre o cuidado do filho ao longo do primeiro mês de vida desse. As participantes revelaram dificuldades no manejo do aleitamento materno, retorno gástrico, cólica e integridade da pele da criança, assim como medos e limites vividos para cuidar da criança. Os resultados estão apresentados a partir de categorias temáticas e trazem os efeitos da intervenção educativa para o enfretamento destas situações. A intervenção educativa contribuiu com o cuidado materno, porém reforça-se a importância de ações contínuas e próximas.

\section{EDUCATIONAL INTERVENTION IN PRENATAL CARE AND NEWBORN CARE}

This study aimed to describe the influence of educational activities developed in prenatal care in the management of complications in child care. It is a study developed through a qualitative approach supported by the references of Symbolic Interaction and Thematic Content Analysis of Bardin. Seven mothers who integrated an educational intervention in prenatal care were interviewed about child care during the first month of it's life. The participants revealed difficulties in the management of breast-feeding, gastric return, colic and child skin integrity, as well as fears and limitations in caring care for the child. Results are presented throughout themes and report the effects of the educational intervention for coping such situations. The educational intervention contributed for the mother care, but was insufficient, pointing out the importance of continuous and proximity actions. 


\section{INTRODUÇÃo}

Valorizar o encontro nas relações de cuidado em saúde é premente e, especificamente no pré-natal favorece vínculo e empoderamento para as demandas típicas à maternidade (BRASIL, 2002). Porém, o cuidado pré-natal no Brasil demonstra-se centrado em queixas físicas e esvaído de diálogo (AMORIM et al., 2019). Dessa forma, tem sua qualidade comprometida, com repercussões longitudinais à saúde, inclusive aquelas de interface com a primeira infância (GOMES et al., 2015).

Portanto, efetivar acolhimento no período gestacional engloba olhares longitudinais, valorização da intersubjetividade, quando ações de suporte à mulher e família para vivenciar a gestação, o parto e nascimento, a parentalidade e o cuidado à criança de forma positiva estão indicadas (FOSTER; OLIVEIRA; BRANDÃO, 2017). Diretrizes políticas voltadas ao desenvolvimento infantil também enfatizam a importância do apoio e promoção da parentalidade em busca de ações positivas no cuidado aos filhos (BRASIL, 2012). Assim, intervenções estruturadas na parentalidade podem produzir desdobramentos no cuidado parental e são pertinentes ao cuidado pré-natal (ROBLES, 2015).

A qualificação da assistência pré-natal, segundo o Ministério da Saúde brasileiro, envolve, dentre outras questões, investimentos em ações educativas (BRASIL, 2013). Essas, ao estarem apoiadas em processos ativos e intersubjetivos, possibilitam à mulher ampliar conhecimentos e práticas que se desdobram em maior segurança e tranquilidade no gestar, parir e parentar (FOGAÇA et al., 2017).

Este artigo traz os resultados de estudo cujo objetivo foi de descrever a influência de ação educativa desenvolvida no pré-natal no manejo de intercorrências no cuidado do filho.

\section{Metodologia}

Trata-se de um estudo de abordagem qualitativa apoiado nos referenciais do Interacionismo Simbólico e Análise de Conteúdo Temática de Bardin.

Para o Interacionismo Simbólico (IS) importa o significado, a interação social dinâmica entre os seres humanos mediados pela sociedade. A premissa básica do IS é a de que o comportamento humano está conectado com o significado dos objetos. Conforme Blumer (1969) o IS está baseado em três premissas: Na primeira, o ser humano age em relação a tudo que compõe o mundo ao seu redor a partir dos significados por ele atribuídos; Na segunda premissa, estes significados são derivados, ou surgem da interação social que têm com os semelhantes; Na terceira, os significados podem ser modificados pelo ser humano por meio de um processo interpretativo ao interagir com tudo o que compõe o mundo ao seu redor.

A análise de Conteúdo desenvolvida por Bardin (2011), com um caráter essencialmente qualitativo enquanto método de organização e análise dos dados, possui algumas características como aceitar que o seu foco seja qualificar as vivências do sujeito, bem como suas percepções sobre determinado objeto e seus fenômenos que se constitui de várias técnicas onde se busca descrever o conteúdo emitido no processo de comunicação, seja ele por meio de falas ou de textos. Bardin (2011) coloca ainda como um conjunto de técnicas de investigação que, tem por finalidade a interpretação destas mesmas comunicações.

O presente artigo derivou de estudo qualitativo voltado a avaliar os impactos de atividade extensionista denominada "Encontros de Diálogo (ED) no pré-natal". O ED consistia em espaço de intervenção educativa de abordagem dialógica direcionada às gestantes adscritas a uma Estratégia Saúde da Família (ESF) de área rural de município do interior paulista. A mediação do ED buscava mobilizar saberes e práticas acerca de temáticas elencadas por seus participantes e postas em conversação, sobretudo em termos de formulação de questões, reflexões e compartilhamento de experiências. Tais encontros eram quinzenais e ocorreram entre outubro de 2014 e outubro de 2015.

Da atividade ED participaram 15 mulheres ao longo do período e dessas, sete integraram o estudo por 
atenderem aos critérios: (a) de inclusão: ter integrado um mínimo de quatro ED; ser maior de 18 anos ou emancipada e ser a criança gestada ao longo do ED nascida de termo (entre 37 e 42 semanas de gestação); e, (b) de exclusão: ter alguma limitação que inviabilizasse narrativa compreensível e ter a criança gestada algum diagnóstico genético ou congênito. Das 8 mulheres não inclusas, o principal motivo $(\mathrm{n}=6)$ esteve relacionado ao fato de não ter atingido o número mínimo de participação nos ED.

A coleta dos dados do estudo aconteceu no decorrer de 2015, próximo ao primeiro mês de vida da criança, por meio de entrevistas em profundidade na residência das puérperas. A colocação "Conte-me como foi cuidar do seu bebê ao longo desse primeiro mês" disparou a entrevistas, que foram gravadas em áudio, transcritas na íntegra e submetidas à análise de conteúdo temática, segundo Bardin (2011).

$\mathrm{Na}$ análise buscou-se conteúdos relativos à experiência de cuidado ao filho, com atenção ao manejo das intercorrências de saúde da criança vivenciadas. Os procedimentos consistiram em: (1) leituras reiterativas dos textos derivados das entrevistas para apreensão do fenômeno e identificação de conteúdos significativos; (2) novas leituras reiterativas e reflexivas para seleção de termos e trechos que permitissem extrair conteúdos estruturantes do fenomeno; (3) análise interpretativa e indutiva do material destacado na etapa anterior com vistas a um agrupamento temático (BARDIN, 2011), a partir do qual os resultados estão apresentados.

O Interacionismo Simbólico (IS) foi o referencial teórico selecionado, uma vez que ele se volta à compreensão do modo como os indivíduos interpretam os objetos sociais e como tal interpretação conduz ao comportamento individual (CHARON, 2010).

O estudo foi aprovado pelo Comitê de Ética em Pesquisa da Universidade Federal de São Carlos, São Paulo, Brasil, pelo Parecer de número 957.814 e Certificado de Apresentação para Apreciação Ética (CAAE) 41721415.9.0000.5504. Todos os participantes assinaram o Termo de Consentimento Livre e Esclarecido. As falas estão identificadas por codinomes escolhidos pelas próprias participantes.

\section{RESULTADOS E Discussão}

Integraram o estudo sete puérperas, com idades entre 17 e 36 anos, quatro em sua segunda paridade e três na primeira. Todas vivenciaram intercorrências no cuidado ao filho nascido a termo ao longo de seu primeiro mês de vida, com contribuições do ED para seu manejo. As categorias temáticas abaixo descrevem o experienciado.

\section{INTERCORRÊNCIAS NO ALEITAMENTO MATERNO}

Todas as mulheres enfrentaram dificuldades com o aleitamento materna (AM) desde a maternidade, em particular relativa à pega, apojadura e produção e esvaziamento mamário.

As primeiras mamadas são apontadas como as mais desafiadoras, com necessidade e desejo de suporte. Nesse sentido, os saberes discutidos nos ED foram relevantes; porém, insuficientes, de forma que o apoio direto é desejado. Na existência de acolhimento próximo da equipe de enfermagem do alojamento conjunto há um diferencial.

O peito rachou mais nos primeiros dias, lá na maternidade. [...] Continuei assim mesmo (a amamentar), porque sabia do grupo (ED) que mesmo quando ele está rachado assim, se a criança pegar certo, daí ele não dói tanto, dói se ela continuar pegando errado. E foi de lá (do ED) que percebi que ela estava pegando errado. Desde a maternidade eu percebi. (Ângela)

Levaram eu para o quarto onde ficam as mulheres com os nenéns (alojamento conjunto), ... aí chegou a hora da primeira mamada. Eu não estava conseguindo, porque ela não esta- 
va conseguindo pegar. Muito tenso. Aí as 'enfermeiras' me ajudaram e ela conseguiu pegar. [...]. A ajuda foi (pensa) muito importante nas primeiras. (Anita)

Retomar consigo, em reflexão, o conversado nos ED e tecer um paralelo com sua situação, contribuía com o diagnóstico do que estavam a passar, bem como com a persistência em manejar as intercorrências.

Aí eu fui falando para mim o que falávamos no grupo, de pegar a maior parte da aréola que chama né!? Ai ela num pegava tudo, mas ela pegava a maior parte, e já não doía tanto, pegou e agora ela pega certo. [...] Eu esperava ela abrir bem a boca, aí eu colocava, empurrava. [...] se deixar ela ainda pega só o bico, só o bico. [...] Aí eu coloco o dedo aqui no canto, pra ela pode soltar, passo o leite que nem as meninas falaram lá (ED). E assim fui indo. (Ângela)

Sentem insegurança em relação à leitura de saciedade do filho, pois visualizam sinais interpretados por elas como de fome. Ponderar sobre o discutido no ED auxilia a confortarem-se e não introduzirem o complemento, fato que tem, também no acolhimento da USF um reforço.

[...] lembrava muito do grupo (ED) quando ela estava muito esfomeada, que ela queria os dois (peitos). É difícil, tem hora que você pensa será que está alimentando ela direito? Fica a dúvida. Daí falava lembra do grupo (ED), ela está crescendo, está saudável. [...] e quando eu chegava lá no postinho eles conversavam e mostravam que estava tudo bem. (Jéssica)

Porém, dentre as sete mães, uma introduziu por conta própria o leite de vaca como complemento por significar ser de contribuição ao crescimento da criança.

Foi por minha conta! Eu falei, vou dar (leite de vaca), vai ajudar! Eu mesmo decidi assim para crescer melhor. (Regina)

As mulheres reconhecem seus esforços e ficam felizes em perceber que estão sendo exitosas no AM do filho, inclusive a que complementou. Tem, no ato do AM, oportunidade para interação íntima e de estimulação com a criança, notando desdobramentos ao vínculo, temáticas exploradas no ED.

Eu consegui, e quero dar de mamar bastante para ela (fala com entusiasmo e felicidade) [...] eu pretendo dar de mamar até uns dois anos e meio, que é a idade certa né!? [...] Eu dou só o leite materno mesmo (expressa satisfação). (Ângela)

Eu pegava, amamentava, conversava bastante com ela, para olhar nos olhos do bebê e falar: 'mãe está aqui, eu vou te passar aquela parte assim de segurança sabe? Pode contar com a mãe’. Eu converso muito com ela, aí coço a cabecinha dela, ela começa a chorar eu cheiro o pescoço dela; então assim, consigo acalmar ela. Dar de mama constrói sim um vínculo. Na parte de amamentar, de conversar. É muito bom, é como falamos lá (ED). (Bruna)

A partir dos achados, podemos perceber que o AM pode efetivar-se enquanto uma meta desejada e buscada pela mulher, na medida em que seu significado abarque elementos relativos ao bem-estar da criança, mas também agregue reconhecimento à mulher enquanto pessoa. Dessa forma, as interações sociais ao longo do pré-natal, por toda a rede de atenção, precisam contribuir na socialização desta mulher ampliando a ponderação de elementos a partir dos quais o significado do ato de aleitar seja estabelecido.

As ações de promoção da amamentação devem considerar a complexidade deste fenômeno que se 
constrói histórica e socialmente, conjugando elementos biológicos e elementos subjetivos da experiência da mulher (ALVES et al., 2018). As experiências e expectativas culturais em relação ao AM dão sentido aos motivos e crenças que norteiam as escolhas maternas no momento de amamentar (ALGARVES; JULIÃO; COSTA, 2015). Portanto, não pode se limitar a ser dialogado na perspectiva de seus benefícios à criança e do dever materno praticar o AM exclusivo.

A aproximação entre cultura profissional e a cultura materna constitui-se um desafio para a efetividade do aconselhamento na amamentação (SILVA et al., 2017). O ED denotou ser um espaço propício a tal aproximação, uma vez que, o nele veiculado, foi várias vezes retomado em autorreflexão pela mulher.

\section{EVENTOS GASTROINTESTINAIS}

Algumas das mulheres $(n=3)$ experienciaram o retorno gástrico de leite pela criança, quando cogitaram a preocupação em ser refluxo gastresofágico (RGE), pois esse foi abordado nos ED. Para todas elas, a avaliação clínica da criança descartou tal suspeita e a relacionou com o volume de leite ingerido.

Toda vez que ele mamava, mesmo que ele arrotava, ele regurgitava e eu achava que podia ser refluxo dele, igual foi dito no grupo (ED). Aí o doutor disse que era normal, porque ele mamava muito e o estômago dele é pequenininho ainda. [...] e todo mundo que eu perguntava falava isso, que é mamar demais. (Sara)

Contudo, tal intercorrência esteve, em duas delas, atrelada o engasgo, quando viveram grande angústia e medo da perda da criança, em especial pelo seu despreparo em intervir.

Aí foi na hora que eu já chupei o nariz dela, a boca, fiz isso três vezes, não saiu, aí massageei as costas dela. [...] aí ela vomitou. Vomitou umas três vezes. Aquilo descia, bastante leite coalhado. Que desespero e eu ali sem saber direito o que fazer. Horrível, que medo de perder ela. (Bruna)

A presença da cólica infantil na criança ocorreu com todas, trouxe angústias e foi associada, sobretudo, com a forma como a criança mamava, dado o entendimento de que a pega inadequada causava deglutição de ar e consequentemente cólica. A identificação da cólica é feita pelos sinais emitidos pela criança, mencionados como aprendidos no ED.

Acho que aconteceu faz uns dias, que ela pegava (o seio) e soltava, pegava e soltava. Acho que entra mais ar e dá cólica. [...] ela chora forte, fica com as perninhas mexendo muito! A carinha fica vermelha! É, ela tem mais assim de manhã, na hora do almoço e a tarde! Tem tudo aquilo que foi falado no grupo (ED" (Ângela)

Para a cólica, fazem uso de medicação sob orientação do pediatra da USF, mas associam práticas não farmacológicas compartilhadas no ED, no intuito de contribuir com o conforto da criança.

Ele (o pediatra da unidade de saúde) passou um remedinho para gases para ela. Eu acho que é 2 gotinhas. Aí eu dou duas gotinhas e depois de um tempo passa. Mas as perninhas dela não param. (Jéssica)

Então, o banho no balde também ajudou bastante! [...] Aí eu dava banho, deixava ele lá dentro e deixava ele relaxar, aí eu tirava e ele já não continuava mais chorando. [...] Os exercícios das perninhas deu certo também, ajuda a soltar os gases de dentro, deu bastante certo sim! Exercícios que eu fiz bastante com as perninhas, acho que tudo que apareceu lá 
No manejo da cólica, tiveram que lidar com sugestões vindas de sua rede social e fortemente pautadas em crenças e mitos, quando o conhecimento advindo das discussões no ED, ajudaram-na a lidar com as mesmas.

Da cólica já falaram até de fazer suco de limão assim sem açúcar, colocar na boca, eu falei imagina!! (risos) que suco de limão vai tirar a dor (risos) imagina, ai eu fui também pelo remedinho, pelo banho mas, conversar ali no grupo (ED) ajudou, ajudou a gente a pensar mais que o remédio, ajudou a explicar para o povo. (Anita)

Duas mães enfrentaram a falta de evacuação por dias em sua criança, fato que as preocupou em termos de normalidade. Buscaram o serviço de saúde, que explanou ser pela alta absortividade do leite materno. Cabe destacar que uma dessas mães foi a que introduziu leite de vaca.

Fora ele ficar esses 3 dias sem fazer cocô. Eu tentava fazer massagem, ele não fazia, eu estava tão preocupada, liguei para as meninas (do ED) pra saber né!? [...] Aí eu comentei com a minha mãe, minha mãe falou 'Faz massagem na barriguinha dele, pega um oleozinho esquenta na sua mão e passa' e ela falou 'leva esse menino no medico não é normal não'. Mas graças a Deus ele fez depois e o doutor explicou ser de eu dar só o leite materno. (Sara)

Manifestações vinculadas ao funcionamento gastrointestinal, seja em termos de evacuação, ou fatores ligados à sua imaturidade, como no caso do retorno gástrico e a cólica infantil, trouxeram preocupações e angústias às mulheres por inseguranças quanto à sua normalidade. Deter conhecimentos elementares que as permite pensar mais criticamente sobre o vivido, contribui com estabelecimento de estratégias ao enfrentamento e, nesse sentido, ressalta-se a relevância dos processos pedagógicos adotados nas ações de educação em saúde. Recursos que ampliam dialogicidade e reflexão crítica estão recomendados (OKANE, 2016), como foi o caso do ED.

Ao considerar ser o engasgo na fase neonatal enquanto uma intercorrência relativamente comum e de potencial para asfixia, pode-se considerar oportunidades de debatê-la em espaços educativos, na pertinência em que a pauta em diálogo assim permitir (PUCCINI, 2015).

\section{MEdOS E LIMITES NO CUIDAdO DA CRIANÇA}

Dentre os cuidados com a criança, aqueles com o coto umbilical foram desafiantes, com inseguranças e medo em termos de dor ou lesão. Saberes mobilizados no ED são resgatados em conjunto com orientações obtidas na maternidade e na ESF, com vistas a tomadas de ação e manejo das recomendações vindas do entorno social, fortemente impregnadas de mitos e crenças.

Eu fiquei boba, que caiu em 5 dias o umbiguinho dele, nunca tinha cuidado de um umbiguinho, foi muito fácil, eu achava que ia ser complicado, eu tinha medo, mas fiz como falaram no grupo (ED), no pré-natal, na maternidade. Todos falaram igual. Daí eu estava na certeza de como era. Só que antes tinha pavor de pensar em tocar, em dar dor, machucar. (Sara)

A recuperação da cesariana trouxe limitações para as mães assumirem o cuidado de seus filhos, quando o apoio de sua mãe e familiares foi necessário, mas suscitaram sentimentos como ciúmes e medo das consequências à ligação mãe-bebê. Tais mães sinalizaram que desempenhar os cuidados diretos à criança integram necessidades maternas no tempo puerperal. 
Eu queria dar banho nos primeiros dias e não conseguia dar banho! Queria trocar e não conseguia, aquilo foi me incomodando [...] Assim, a vida ativa que eu fazia, aquele serviço, minha mãe fazia pra mim. Eu não estava tendo condições de fazer. Achava que aquele momento era um momento meu sabe!? De dar banho de primeiro dia, limpar o "umbigo" $e$ tudo. [...] Aquele momento ali que eu, queria que fosse meu sabe!? Mas foi minha mãe que cuidou. [...] acreditava assim naquela primeira imagem pra passar aquela boa impressão de mãe pra filho sabe!? Para ter aquela ligação! 'Filho eu sou sua mãe, sua mãe está aqui', sabe!? (Bruna)

O cuidado com o coto umbilical traz inseguranças maternas por ser significado como algo frágil e que pode causar dor e incomodo para a criança quando manipulado, fato presente em outro estudo (ALMEIDA et al., 2016). O ED favoreceu transposição desse temor, assim como o manejo e a administração de práticas populares intergeracionais. Percebe-se contribuições do ED para a autonomia da mulher no cuidado ao filho.

Os atos de cuidado ao filho agregam significado simbólico importante à construção do papel materno. Assim, ter limitações físicas para desempenhá-los produzidas por cesariana remete-nos a retomar e agregar a sinalização de tal prática ser adotada na sua real indicação.

A taxa de cesarianas no Brasil atingiu 57\% em 2014. As regiões Centro-Oeste, Sul e Sudeste registraram taxas acima da média nacional, com 63\%, 62\% e 61 (DATASUS). A taxa de cesárea quando desagregada para a saúde suplementar e para o SUS é de $90 \%$ e 45\%, respectivamente. As limitações físicas para o cuidado fazem parte da vivência de muitas mulheres, o que remete a reflexões acerca do impacto das cesarianas desnecessárias no desempenho de ações vinculadas à maternagem (MEDEIROS; MARCELINO, 2018).

Em relação ao apoio familiar, a figura da avó aparece e confirma a centralidade das figuras femininas no seio familiar quando o assunto é cuidado de crianças pequenas (CARDOSO; VIVIAN, 2017).

As participantes destacaram dificuldades no cuidado ao filho ao longo do primeiro mês de vida, quando o cuidado em saúde ainda se mostra com insuficiências no apoio e promoção da autonomia na parentalidade. É essencial, aos profissionais de saúde, que tenham atitude de acolhimento e disponibilidade para escuta e esclarecimento de aflições, com consideração da singularidade de cada situação (ALMEIDA; LUZ, 2015). É no esforço e compromisso com a valorização do encontro no cuidado em saúde ao longo de toda a Rede de Atenção à Saúde (RAS) que o processo de autonomia parental pode ser efetivamente apoiado, incluindo ações como o ED.

Pelo exposto acima se identificou que o ED, estratégia coletiva de intervenção dialógica e educativa no pré-natal, teve suas contribuições ao cuidado materno da criança; porém, tem íntima dependência e conexão com as demais práticas do cuidado em saúde no pré-natal, parto e puerpério. Assim, isoladamente, tal ação fica na insuficiência; sobretudo, quando há incipiências de acolhimento na longitudinalidade do cuidado em saúde na RAS.

\section{CONCLUSÃo}

A mulher que integrou ED vivencia dificuldades relativas ao cuidado da criança e, no enfrentamento, os conhecimentos adquiridos nesse espaço contribuem para sua autonomia. Ao se ponderar a integralidade e resolutividade, tem dependência do acolhimento no cuidado em saúde ao longo de toda a RAS, mas a potencialidade do encontro é confirmada, reforçando-a enquanto desafio ao cuidado em saúde, sobretudo em termos de grupos dialógicos.

Os ED propiciaram, à mulher, a oportunidade da abertura para o novo e para a desmistificação de saberes, agregando conhecimentos científicos que se tornam potencialidades de cuidado para o bebê que chega à família. Faz-se premente que estratégias como essa constituam práticas cotidianas do enfermeiro, 
uma vez que traz, em sua essência, a educação em saúde de modo a permitir o empoderamento da mulher.

Os resultados apontam também para a necessidade de acompanhamento próximo de profissionais de saúde neste primeiro mês de cuidado materno à criança. Tanto primíparas quanto multíparas clamam por suporte para enfrentar os desafios postos pelo cuidado à criança e, nesse sentido desejam efetivar intersubjetividades. Apesar de se referir a uma experiência particular, evidências aqui relatadas confirmam a interação e a escuta junto a um coletivo enquanto de acolhimento e emancipação, com recomendações de ampliação para a promoção de saúde.

\section{REFERÊNCIAS}

ALGARVES, T. R.; JULIÃO, A. M. S.; COSTA, H. M. Aleitamento materno: influência de mitos e crenças no desmame precoce. Rev. Saúde em foco, Teresina, v. 2, n. 1, art. 10, p. 151-167, jan./jul. 2015.

ALMEIDA J. M, Luz SAB, Ued FV. Apoio ao aleitamento materno pelos profissionais de saúde: revisão integrativa da literatura. Rev Paul Pediatr. vol. 33, p. 355-62, 2015.

ALMEIDA, J. M.; LINHARES, E. F; DIAS, J. A. A.; LÔBO, M. P.; REIS, A. S. F.; NERY, P. I. G. Prática educativa no cuidado ao coto umbilical: relato de experiência. Rev enferm UFPE on line., Recife, 10(Supl. 5):4383-8, nov., 2016.

ALVES, T. R. M.; CARVALHO, J. B. L.; LOPES, T. R. G.; SILVA, G. W. S. S.; TEIXEIRA, G. A. Contribuições de enfermeiros na promoção do aleitamento materno exclusivo. Rev Rene. 2018;19:e33072.

AMORIM, T. S.; BACKES, M. T. S.; SANTOS, E. K. A.; CUNHA, K. S.; COLLAÇO, V. S. Assistência obstétrica/neonatal: ampliação da prática clínica do enfermeiro na Atenção Primária. Acta paul. enferm. vol.32 no.4 São Paulo July/Aug. 2019 Epub Aug 12, 2019.

BARDIN, L. Análise de conteúdo. 5a reimpressão. São Paulo: Edições 70; p. 276, 2011.

BLUMER, H. Symbolic interactionism: perspective and method. Berkeley: University of California Press, 1969.

BRASIL, Ministério da Saúde. Departamento de Informática do SUS (DATASUS). Indicadores de Saúde [acessado 2019 Dez 09]. Disponível em: http://www2.datasus.gov.br/DATASUS/index.php?area=0205

CARDOSO, A. C. A.; VIVIAN, A. G. Maternidade e Suas Vicissitudes: a importância do apoio social no desenvolvimento da díade mãe-bebê. Diaphora | Porto Alegre, v. 17 (1),| jan/dez 2017.

CHARON, J. M. Symbolic interactionism: an introduction, an interpretation, an integration. 10 ed. Boston: Prentice Hall, 2010.

FOGAÇA, N. R.; FERRARI, R. A. P.; GABANI, F. L.; SOARES, N. T. I.; TACLA, M. T. G. M.; OLIVEIRA, G. S. Operacionalização de grupos de pré-natal: percepção dos profissionais do serviço da atenção primária à saúde. Revista Pesquisa Qualitativa. São Paulo (SP), v. 5, n. 7, p. 128-142, abr. 2017. 
FOSTER, L. B.; OLIVEIRA, M. A.; BRANDÃO, S. M. O. C. O acolhimento nos moldes da humanização aplicada ao processo de trabalho do enfermeiro no pré-natal. Rev enferm UFPE on line., Recife, 11(Supl. 10):4617-24, out., 2017.

GOMES ALM, Rocha CR, Henrique DM, Santos MA, Silva LR. Conhecimentos de familiares sobre os cuidados com recém-nascidos. Rev Rene. 2015; vol. 16, p. 65-258.

MEDEIROS, T. M. L.; MARCELINO, J. F. Q. Percepção de puérperas sobre o seu desempenho ocupacional no pós-operatório da cesariana. Cad. Bras. Ter. Ocup., São Carlos, v. 26, n. 1, p. 97-109, 2018.

BRASIL, Ministério da Saúde. Secretaria de Políticas de Saúde. Departamento de Atenção Básica. Saúde da criança: acompanhamento do crescimento e desenvolvimento infantil/Ministério da Saúde. Brasília: Ministério da Saúde. 2012.

BRASIL, Ministério da Saúde. Política Nacional de Humanização. Rede Humaniza SUS. Brasília: Ministério da Saúde. 2013.

BRASIL, Ministério da Saúde. Programa de humanização do parto: humanização no Pré - Natal e Nascimento. Brasília, 2002.

OKAME ESH, Oliveira BB. Estratégias de ensino para educação e saúde: revisão integrativa. R Eletr de Extensão. vol. 13, p. 138-51, 2016.

PUCCINIFRS, Berretin-Felix G. Refluxo gastroesofágico e deglutição em recém nascidos e lactentes: revisão integrativa da literatura. Rev. CEFAC [Internet]. 2015; vol. 17, p.73-1664.

ROBLES, A. F. Regulações do corpo e da parentalidade durante o pré-natal em mulheres jovens de camadas populares. Civitas, Porto Alegre, v. 15, n. 2, p. 190-213, abr.-jun. 2015.

SILVA, D. S. S.; OLIVEIRA, M.; SOUZA, A. L. T. D.; SILVA, R. M. Promoção do aleitamento materno: políticas públicas e atuação do enfermeiro. Cadernos UniFOA, Volta Redonda, n. 35, p. 135-140, dez. 2017. 